\title{
Sistem Diagnosis Penyakit pada Kambing Menggunakan Metode Forward Chaining
}

\author{
Ima Apriliya ${ }^{1}$, Ida Wahyuni ${ }^{2}$ \\ ${ }^{1,2}$ Fakultas Teknik Informatika, STMIK Asia Malang \\ 1imaapriliya93@gmail.com,2idawahyuni@asia.ac.id
}

\begin{abstract}
ABSTRAK. Kambing adalah binatang pemamah biak dan pemakan rumput. Dalam membudidayakan kambing, para pemilik kambing rata-rata mempunyai pengetahuan yang kurang dalam hal penyakit yang menyerang kambing peliharaan mereka.Sistem pakar mulai digunakan untuk membantu seorang pakar atau ahli dalam mendiagnosis penyakit pada kambing berdasarkan gejala yang ada. Tujuan dan manfaat dari Diagnosis penyakit kambing antara lain adalah mempermudah dan mempercepat mengetahui jenis penyakit yang menyerang kambing. Untuk mengetahui diagnosis penyakit kambing, peneliti membuat sistem pakar dengan menerapkan metode forward chaining. Diagnosis penyakit kambing menggunakan metode Forward Chaining.Pada penelitian ini jenis penyakit yang dapat didiagnosis sebanyak 16 penyakit.Pengujian yang digunakan yaitu pengujian akurasi dengan data uji sebanyak 16 penyakit dengan tingkat akurasi sebesar $100 \%$. Kesimpulan dari penelitian yang telah dilakukan berdasarkan permasalahan yang telah diselesaikan melalui pembuatan sistem pakar ini adalah sistem pakar untuk menentukan penyakit kambing dirancang dengan rule base dan metode forward chaining. Jumlah rule yang digunakan sebanyak 16 rule dengan 43 jenis pertanyaan sesuai dengan jumlah gejala.
\end{abstract}

Kata Kunci: Diagnosis; Forward Chaining; Penyakit Kambing; Sistem Pakar.

ABSTRACT. Goats are ruminants and grazers. In cultivating goats, the average goat owners have less knowledge in terms of diseases that attack their domestic goats. Expert systems began to be used to help an expert or expert in diagnosing disease in goats based on existing symptoms. Objectives and benefits of Diagnosis goat disease, among others, is to facilitate and accelerate knowing the type of disease that attacks the goat. To determine the diagnosis of goat disease, researchers create expert system by applying forward chaining method. Diagnose goat disease using Forward Chaining method. In this study the types of diseases that can be diagnosed as much as 16 diseases. Testing used is the test of accuracy with test data of 16 diseases with an accuracy rate of $100 \%$. The conclusion of the research that has been done based on the problems that have been resolved through the manufacture of this expert system is expert system to determine goat disease designed with rule base and forward chaining method. The number of rules used as many as 16 rules with 43 types of questions in accordance with the number of symptoms.

Keywords: Diagnosis; Forward Chaining; Goat Disease; Expert system.

\section{PENDAhuluan}

Kambing menurut Kamus Besar Bahasa Indonesia adalah binatang pemamah biak dan pemakan rumput atau daun-daunan, berkuku genap, tanduk bergeronggang, dan dipelihara sebagai hewan ternak untuk diambil daging, susu, dan bulunya. Kambing merupakan salah satu ternak unggulan dibeberapa wilayah di Indonesia(Nurdiansyah, Destiani, \& Retnadi, 2013). Tingginya produksi kambing di Indonesia dikarenakan kambing dapat dimanfaatkan mulai dari daging hingga kulitnya. Saat ini daging salah satu bahan pangan yang penting untuk mencukupi gizi masyarakat dan sangat mudah untuk diperdagangkan(Diwyanto, Priyanti, \& Inounu, 2005). Menurut Djajanegara \& Misniwaty (2002) konsumsi daging kambing pada tahun 2001 meningkat sebesar 5,28 kg/kapita pertahun atau 2,49 g/kapita perhari dengan peningkatan rata-rata 3,6 persen/kapita pertahun. Permintaan kambing jantan semakin besar dari tahun ke tahun ketika perayaan Idul Adha sehingga berakibat perlunya mencukupi kebutuhan dengan mengatur pola produksi.

Dalam membudidayakan kambing, para pemilik kambing rata-rata mempunyai pengetahuan yang kurang dalam hal penyakit yang menyerang kambing peliharaan mereka. Ketika kambing terserang penyakit dan sudah akan mati biasanya pemilik kambing akan segera menyembelih kambing sebelum kambing mati. Agar penanganan terhadap penyakit kambing dapat dilakukan dengan cepat, dibutuhkan sistem pakar yang dapat digunakan untuk membantu pemilik kambing dalam mendiagnosis penyakit pada kambing berdasarkan gejala yang ada (Nurdiansyah et al., 2013).

Sistem Pakar adalah suatu program komputer yang dirancang untuk memodelkan kemampuan penyelesaian masalah yang dilakukan oleh seorang pakar.Sistem pakar atau expert system dibuat bertujuan untuk dapat menyelesaikan masalah yang cukup rumit yang sebenarnya hanya bisa diselesaikan oleh para 
ahli. Pembuatan sistem pakar bukan untuk menggantikan ahli itu sendiri melainkan dapat digunakan sebagai asisten yang sangat berpengalaman (Kusumadewi, 2010).

Sistem pakar pernah digunakan untuk mendeteksi penyakit kambing yang dilakukan oleh Orisa, Santoso, \& Setyawati (2014)dengan akurasi pada pakar 1 menghasilkan 84\% dan pakar 2 menghasilkan akurasi $80 \%$. Penelitian lain juga pernah dilakukan oleh Wati \& Mardiana (2014)untuk mendeteksi pendarahan pada masa kehamilan dengan akurasi 100\%. Dari penelitian sebelumnya, sistem pakar dapat melakukan prediksi dengan akurasi yang cukup baik, sehingga dalam penelitian ini, akan digunakan sistem pakar untuk mendeteksi penyakit pada kambing. Jumlah penyakit yang akan dideteksi ada 16 penyakit dengan 43 gejala.

\section{KAJIAN PUSTAKA}

\subsection{Hewan Mamalia}

Menurut Kamus Besar Bahasa Indonesia pengertian dari mamalia adalah kelompok binatang vertebrata atau hewan bertulang belakang yang memiliki kelenjar susu untuk menyusui anaknya. Hewan mamalia selalu diidentikkan sebagai hewan yang melahirkan. Tidak semua hewan mamalia berkembang biak dengan cara melahirkan. Ada beberapa ciri-ciri hewan mamalia diantaranya adalah (Nurhakim, 2014):

1. Bertulang belakang

2. Memiliki kelenjar susu

3. Kebanyakan mamalia berkembangbiak dengan melahirkan

4. Memiliki rambut

5. Menyusui

6. Beberapa mamalia dilengkapi kantung pada perut

7. Memiliki kuku pada kakinya

\subsection{Kambing}

Menurut Kamus Besar Bahasa Indonesia kambing adalah binatang pemamah biak dan pemakan rumput (daun-daunan), berkuku genap, tanduknya bergeronggang, biasanya dipelihara sebagai hewan ternak untuk diambil daging, susu, kadang-kadang bulunya. Kambing ternak atau Capra aegagrus hircus adalah subspesies kambing liar yang secara alami tersebar di Asia Barat Daya dan Eropa.Kambing liar jantan maupun betina memiliki tanduk sepasang, namun tanduk pada kambing jantan lebih besar.Umumnya, kambing mempunyai janggut, dahi cembung, ekor agak ke atas, dan kebanyakan berambut lurus dan kasar.

\subsection{Sistem Pakar}

Sistem pakar atau expert system adalah salah satu teknik kecerdasan buatan yang berusaha mengadopsi pengetahuan manusia ke komputer, agar komputer dapat menyelesaikan masalah seperti yang biasa dilakukan oleh para ahli.Sistem pakar yang baik dirancang agar dapat menyelesaikan suatu permasalahan tertentu dengan meniru kerja dari para ahli.Dengan sistem pakar ini, orang awampun dapat menyelesaikan masalah yang sebenarnya hanya dapat diselesaikan dengan bantuan para ahli. Bagi para ahli, sistem pakar ini juga akan membantu aktivitasnya sebagai asisten yang sangat berpengalaman(Kusumadewi, 2010). Sistem pakar terdiri dari dua bagian pokok, yaitu: lingkungan pengembangan (development environment) dan lingkungan konsultasi (consultation environment). Lingkungan pengembangan digunakan sebagai pembangun sistem pakar baik dari segi pembangun komponen maupun basis pengetahuan. Lingkungan konsultasi digunakan oleh seseorang yang bukan ahli untuk berkonsultasi (Turban, 1995).

\subsection{Forward Chaining}

Runut maju forward chaining adalah aturan-aturan diuji satu demi satu dalam urutan tertentu (data driven). Forward chaining merupakan grup dari multiple inferensi yang melakukan pencarian dari suatu masalah kepada solusinya. Jika klausa premis sesuai dengan situasi atau bernilai true, maka proses akan menghasilkan konklusi. Forward chaining adalah data-driven karena inferensi dimulai dengan informasi yang tersedia dan baru konklusi diperoleh.Forward chaining dapat digunakan jika suatu aplikasi menghasilkan tree yang lebar dan tidak dalam(Wahyuni \& Kusumawati, 2017).

\subsection{Flowchart}

Flowchart adalah suatu bagan dengan simbol-simbol tertentu yang menggambarkan urutan proses secara mendetail dan hubungan antara suatu proses (instruksi) dengan proses lainnya dalam suatu program (Widya, 1983). Flowchart menunjukkan atau menggambarkan rangkaian kegiatan-kegiatan program dari 
mulai awal hingga akhir.Inti pembuatan dari flowchart atau Diagram Alir ini adalah menggambarkan urutan langkah-langkah pengerjaan dari suatu algoritma.

\subsection{Data Flow Diagram}

Data Flow Diagram adalah suatu diagram yang menggunakan notasi-notasi untuk menggambarkan arus dari data sistem, yang penggunaannya sangat membantu untuk memahami sistem secara logika, terstruktur dan jelas. Data Flow Diagram (DFD) merupakan alat bantu dalam menggambarkan atau menjelaskan suatu sistem yang sedang berjalan dengan logis. Sumber lain mengatakan bahwa Data Flow Diagram(DFD) merupakan suatu alat yang sering digunakan untuk membuat model, khususnya bila fungsi-fungsi sistem merupakan bagian yang lebih penting dan kompleks daripada data yang dimanipulasi oleh sistem(Brady \& Loonam, 2010).

\section{PERANCANGAN SISTEM PAKAR}

Kambing merupakan salah satu ternak unggulan di Indonesia, sehingga membudidayakan kambing masih diminati sampai saat ini. Membudidayakan kambing terus meningkat seiring dengan meningkatnya kebutuhan kambing mulai dari daging, susu ataupun bulunya. Kebutuhan daging kambing meningkat ketika hari-hari tertentu.

Dalam membudidayakan kambing peternak tidak terlepas dari masalah yang dihadapi yaitu penyakit yang menyerang kambing. Ketika membudidayakan kambing peternak biasanya akan menyembelih kambing yang sudah sakit sebelum mati. Penanganan pada kambing yang sakit diperlukan agar meminimalkan kambing yang mati agar kebutuhan kambing tetap terpenuhi dengan cara mengetahui penyakit kambing dari gejala-gejala yang muncul. Untuk itu diperlukan sistem yang dapat digunakan untuk membantu pemilik kambing.Dibutuhkan sistem pakar untuk membantu pemilik kambing dalam mendiagnosis penyakit berdasarkan gejala yang ada.

Sistem pakar yang akan dibangun digunakan untuk mendiagnosis penyakit pada kambing dengan metode forward chaining yang akan digunakan untuk mencocokkan gejala-gejala yang berupa pertanyaan yang akan dijawab oleh pengguna dengan rule yang ada, kemudian akan didapatkan konklusi. Rule didapat dari kumpulan semua fakta yang merupakan gejala suatu penyakit tertentu kemudian dimasukkan kedalam aturan IF - THEN. Hasil output sistem berupa nama penyakit beserta pengobatan dan pencegahan. Pada Tabel 1 ditunjukkan dengan nama penyakit serta kode penyakit yang akan menjadi acuan dalam pembuatan sistem pakar. Sedangkan pada Tabel 2 akan ditunjukkan dengan kode gejala penyakit dan kemunculan gejalanya yang akan menjadi acuan dalam pembuatan sistem pakar. Dari Tabel 1 dan Tabel 2 dapat dibuat tabel kemunculan gejala pada penyakit yang ditunjukkan pada Tabel 3. Pada Tabel 4 ditunjukkan tabel rule yang digunakan untuk proses inferensi forward chaining.

Tabel 1 Tabel Kode Penyakit dan Jenis Penyakit pada Kambing

\begin{tabular}{lll}
\hline \multicolumn{1}{c}{ Kode } & Jenis Penyakit \\
\hline P01 & Diare & \\
P02 & Radang pusar & \\
P03 & Cacar mulut & \\
P04 & Hipocalsemia \\
P05 & Radang Limpha \\
P06 & Penyakit mulut dan kuku (PMK) \\
P07 & Ngorok (Septicaemia Epizootica) \\
P08 & Perut kembung (Tympany) \\
P09 & Parasit cacing hati \\
P10 & Parasit cacing gelang \\
P11 & Parasit cacing lambung \\
P12 & Parasit cacing mata \\
P13 & Kudis (Scabies) \\
P14 & Dermatitis \\
P15 & Pneumonia \\
P16 & Radang kelenjar susu (Mastitis) \\
\hline \hline
\end{tabular}


Tabel 2 Tabel Kode Gejala Penyakit dan Kemunculan Gejala pada Kambing

\begin{tabular}{|c|c|}
\hline Kode & Gejala \\
\hline G01 & Kambing tampak lesu \\
\hline G02 & Tidak ingin menyusu \\
\hline G03 & Suhu tubuh meninggi \\
\hline G04 & Mengeluarkan kotoran cair dan berbau busuk \\
\hline G05 & Pembengkakan pada sekitar pusar \\
\hline G06 & Panas di bekas potongan tali pusar \\
\hline G07 & Sekeliling pusar berwarna merah \\
\hline G08 & Apabila pusarnya diraba merasa kesakitan \\
\hline G09 & Sukar bernafas \\
\hline G10 & Lidah terjulur \\
\hline G11 & Mulut banyak mengeluarkan cairan \\
\hline G12 & Mulut berbau asam \\
\hline G13 & Selalu gelisah \\
\hline G14 & Timbul kejang-kejang pada beberapa ototnya, bahkan sampai ke seluruh badan \\
\hline G15 & Dari lubang hidung dan dubur keluar cairan bercampur darah \\
\hline G16 & Nadi berjalan cepat \\
\hline G17 & Tubuh gemetar \\
\hline G18 & Nafsu makan hilang. \\
\hline G19 & Mencret dengan kotoran campur darah \\
\hline G20 & Gusi dan permukaan lidah melepuh yang berisi cairan jernih \\
\hline $\mathrm{G} 21$ & Lidah bengkak dan menjulur ke luar \\
\hline G22 & Mulut menganga \\
\hline G23 & Keluar lendir berbuih \\
\hline $\mathrm{G} 24$ & Terdengar ngorok \\
\hline $\mathrm{G} 25$ & Lambung kambing membesar \\
\hline G26 & Menyerap sebagian zat makanan yang seharusnya untuk pertambahan berat tubuh \\
\hline $\mathrm{G} 27$ & Merusak jaringan-jaringan organ vital kambing \\
\hline G28 & Ternak makin lama kondisinya makin memburuk \\
\hline G29 & Badan lemah dan kurus \\
\hline G30 & Sering menggaruk atau menggosok-gosokan badannya \\
\hline G31 & Kulit bersisik dan kering pada muka, telinga, perut, punggung, kaki dan pangkal ekor \\
\hline G32 & Terjadi peradangan kulit di sekitar mulut, kelopak mata dan alat genital \\
\hline G33 & Peradangan pada kelenjar susu pada induk kambing \\
\hline G34 & Batuk-batuk dan sulit bernafas \\
\hline G35 & Terdapat luka di ujung mata \\
\hline G36 & Ambing kambing bengkak \\
\hline G37 & Kulit sekita ambing jika diraba terasa panas \\
\hline G38 & Produksi air susu terhenti atau berkurang. \\
\hline G39 & Mati mendadak \\
\hline G40 & Disela-sela jari atau kuku terdapat bintik merah \\
\hline G41 & Bintik merah di sekitar mulut \\
\hline G42 & Ada kerusakan pada usus \\
\hline G43 & Terdapat kerusakan pada hati \\
\hline
\end{tabular}


Tabel 3 Tabel Kemunculan Gejala pada Penyakit

\begin{tabular}{|c|c|c|c|c|c|c|c|c|c|c|c|c|c|c|c|c|}
\hline \multirow{2}{*}{ Gejala } & \multicolumn{16}{|c|}{ Penyakit } \\
\hline & P01 & P02 & P03 & P04 & P05 & P06 & P07 & P08 & P09 & P10 & P11 & P12 & P13 & P14 & P15 & P16 \\
\hline G01 & $V$ & & $V$ & & & & & & & & & & & & & \\
\hline G02 & $V$ & & & & & & & & & & & & & & & \\
\hline G03 & $V$ & & & & $V$ & $V$ & & & & & & & & & $V$ & $V$ \\
\hline G04 & $V$ & & & & & & & & & & & & & & & \\
\hline G05 & & $V$ & & & & & & & & & & & & & & \\
\hline G06 & & $V$ & & & & & & & & & & & & & & \\
\hline G07 & & $V$ & & & & & & & & & & & & & & \\
\hline G08 & & $V$ & & & & & & & & & & & & & & \\
\hline G09 & & & $V$ & & & & $V$ & & & & & & & & & \\
\hline G10 & & & $V$ & & & & & & & & & & & & & \\
\hline G11 & & & $V$ & & & & & & & & & & & & & \\
\hline G12 & & & V & & & & & & & & & & & & & \\
\hline G13 & & & & $V$ & & & & & & & & & & & & \\
\hline G14 & & & & $V$ & & & & & & & & & & & & \\
\hline G15 & & & & & $V$ & & & & & & & & & & & \\
\hline G16 & & & & & $V$ & & & & & & & & & & & \\
\hline G17 & & & & & $V$ & & & & & & & & & & & \\
\hline G18 & & & & & $V$ & & & & $V$ & & & $V$ & & & $V$ & $V$ \\
\hline G19 & & & & & $V$ & & & & & & & & & & & \\
\hline G20 & & & & & & $V$ & & & & & & & & & & \\
\hline G21 & & & & & & & $V$ & & & & & & & & & \\
\hline G22 & & & & & & & $V$ & & & & & & & & & \\
\hline G23 & & & & & & & $V$ & & & & & & & & & \\
\hline G24 & & & & & & & $V$ & & & & & & & & & \\
\hline G25 & & & & & & & & $V$ & & & & & & & & \\
\hline G26 & & & & & & & & & $V$ & $V$ & $V$ & $V$ & & & & \\
\hline G27 & & & & & & & & & & $V$ & & $V$ & & & & \\
\hline G28 & & & & & & & & & & & & & $V$ & & & \\
\hline G29 & & & & & & & & & & & & & $V$ & & $V$ & \\
\hline G30 & & & & & & & & & & & & & $V$ & & & \\
\hline G31 & & & & & & & & & & & & & $V$ & & & \\
\hline G32 & & & & & & & & & & & & & & $V$ & & \\
\hline G33 & & & & & & & & & & & & & & $V$ & & \\
\hline G34 & & & & & & & & & & & & & & & $V$ & \\
\hline G35 & & & & & & & & & & & & $V$ & & & & \\
\hline G36 & & & & & & & & & & & & & & & & $V$ \\
\hline G37 & & & & & & & & & & & & & & & & $V$ \\
\hline G38 & & & & & & & & & & & & & & & & $V$ \\
\hline G39 & & & & & $V$ & & & & & & & & & & & \\
\hline G40 & & & & & & $V$ & & & & & & & & & & \\
\hline G41 & & & $V$ & & & & & & & & & & & & & \\
\hline G42 & & & & & & & & & & & $V$ & & & & & \\
\hline G43 & & & & & & & & & $V$ & & & & & & & \\
\hline
\end{tabular}

Tabel 4 Daftar Rule

\begin{tabular}{|c|c|}
\hline Rule ke- & Rule \\
\hline 1 & $\begin{array}{l}\text { IF Suhu tubuh meninggi AND Kambing tampak lesu AND Tidak ingin menyusu AND } \\
\text { Mengeluarkan kotoran cair dan berbau busuk THEN Diare }\end{array}$ \\
\hline 2 & $\begin{array}{l}\text { IF Bengkak disekitar pusar AND Panas pada potongan tali pusar AND Sekeliling pusar } \\
\text { berwarna merah AND Pusar diraba akan kesakitan THEN Radang pusar }\end{array}$ \\
\hline 3 & $\begin{array}{l}\text { IF Sulit bernafas AND Lidah terjulur AND Mulut mengeluarkan cairan AND Mulut berbau } \\
\text { asam AND Bintik merah disekitar mulut THEN Cacar mulut }\end{array}$ \\
\hline 4 & IF Kambing merasa gelisah AND Kejang otot di seluruh tubuh THEN Hipocalsemia \\
\hline
\end{tabular}




\begin{tabular}{|c|c|}
\hline Rule ke- & Rule \\
\hline 5 & $\begin{array}{l}\text { IF Suhu tubuh meninggi AND Lubang dubur dan hidung mengeluarkan kotoran bercampur } \\
\text { darah AND mencret dengan kotoran bercampur darah AND nadi berjalan cepat Tubuh } \\
\text { gemetar AND Mati Mendadak THEN Radang Limpha }\end{array}$ \\
\hline 6 & $\begin{array}{l}\text { IF Bintik merah di jari atau kuku AND Gusi dan permukaan lidah melepuh THEN Penyakit } \\
\text { Mulut dan Kuku }\end{array}$ \\
\hline 7 & $\begin{array}{l}\text { IF Sulit bernafas AND Lidah bengkak dan terjulur AND Mulut menganga AND Keluar } \\
\text { Lendir berbuih AND Terdengar ngorok THEN Septicaemia Epizootica }\end{array}$ \\
\hline 8 & IF Lambung terlihat membesar THEN Tympany \\
\hline 9 & $\begin{array}{l}\text { IF Nafsu makan hilang AND Menyerap zat makanan AND Terdapat kerusakan pada hati } \\
\text { THEN Parasit Cacing Hati }\end{array}$ \\
\hline 10 & $\begin{array}{l}\text { IF Nafsu makan hilang AND Menyerap zat makanan AND Merusak organ vital kambing } \\
\text { THEN Parasit Cacing Gelang }\end{array}$ \\
\hline 11 & $\begin{array}{l}\text { IF Nafsu makan hilang AND Menyerap zat makanan AND Terdapat kerusakan pada usus } \\
\text { THEN Parasit Cacing Lambung }\end{array}$ \\
\hline 12 & $\begin{array}{l}\text { IF Nafsu makan hilang AND Menyerap zat makanan AND Terdapat luka diujung mata } \\
\text { THEN Parasit Cacing Mata }\end{array}$ \\
\hline 13 & $\begin{array}{l}\text { IF Nafsu makan hilang AND Sering menggaruk atau menggosok badan AND Badan lemah } \\
\text { dan kurus AND Kondisi memburuk AND Kulit bersisik pada muka telinga perut punggung } \\
\text { kaki atau pangkal ekor THEN Scabies }\end{array}$ \\
\hline 14 & $\begin{array}{l}\text { IF Suhu tubuh meninggi AND Radang kulit disekitar mulut, mata dan area genital AND } \\
\text { peradangan pada kelenjar susu pada induk kambing THEN Dermatitis }\end{array}$ \\
\hline 15 & $\begin{array}{l}\text { IF Nafsu makan hilang AND Badan lemah dan kurus AND Batuk dan sulit bernafas THEN } \\
\text { Pneumonia }\end{array}$ \\
\hline 16 & $\begin{array}{l}\text { IF Nafsu makan hilang AND ambing kambing bengkak AND kulit disekitar ambing terasa } \\
\text { panas AND Produksi air susu berhenti atau berkurang THEN Mastitis }\end{array}$ \\
\hline
\end{tabular}

\subsection{Flowchart Sistem}

Flowchart sistem dimulai dari user memilih Form Menu, kemudian menuju ke Menu Deteksi, dari Menu Deteksi user diminta menjawab pertanyaan dari sistem. Jawaban dari userakan di proses untuk mendapatkan hasil deteksi. Flowchart dari sistem yang diajukan ditunjukkan pada Gambar 1.

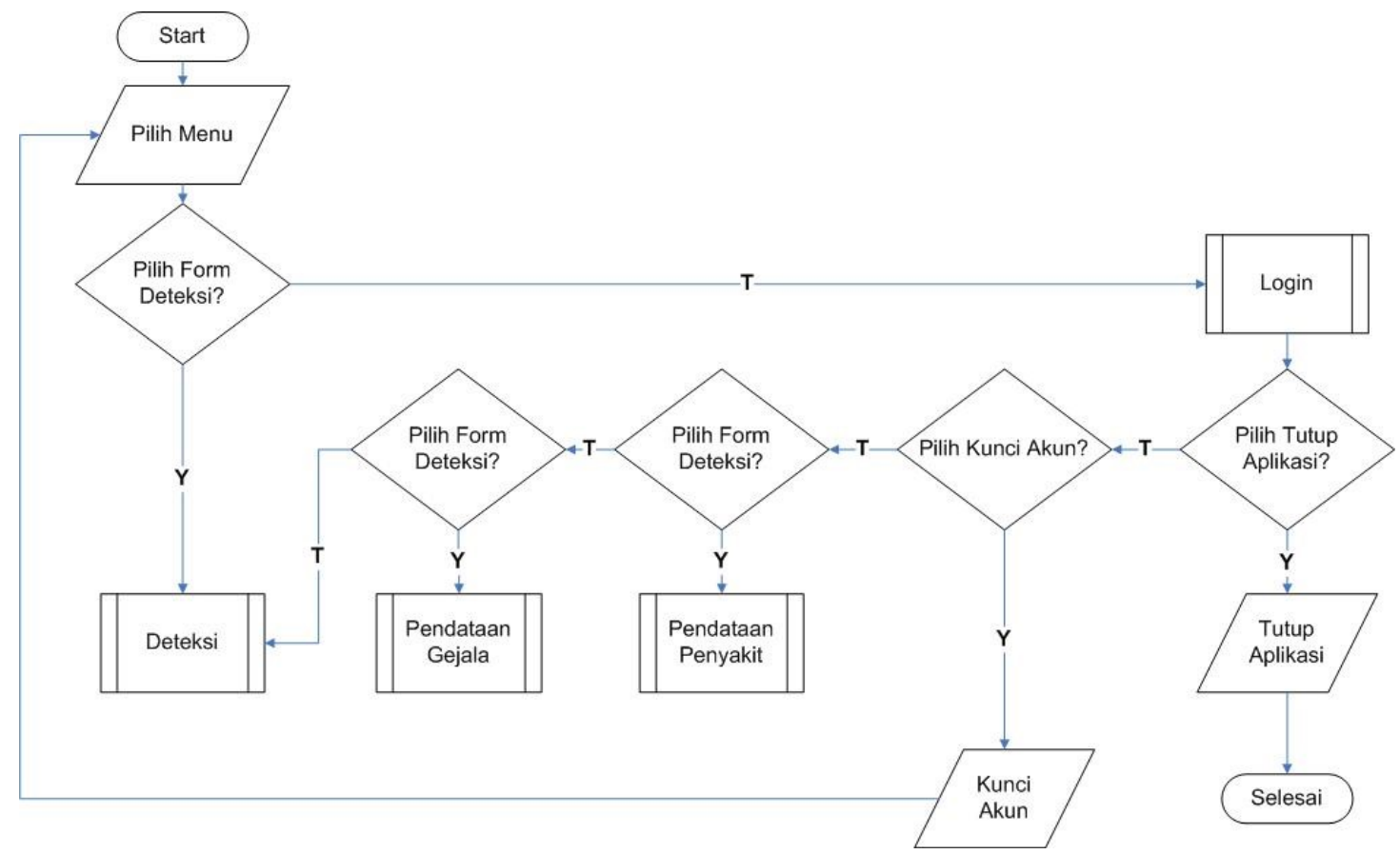

Gambar 1 Flowchart Sistem yang Diajukan 


\subsection{Data Flow Diagram}

Pada sistem ini akan ditunjukkan rancangan Data Flow DiagramLevel 0 dapat ditunjukkan pada Gambar 2 berikut:

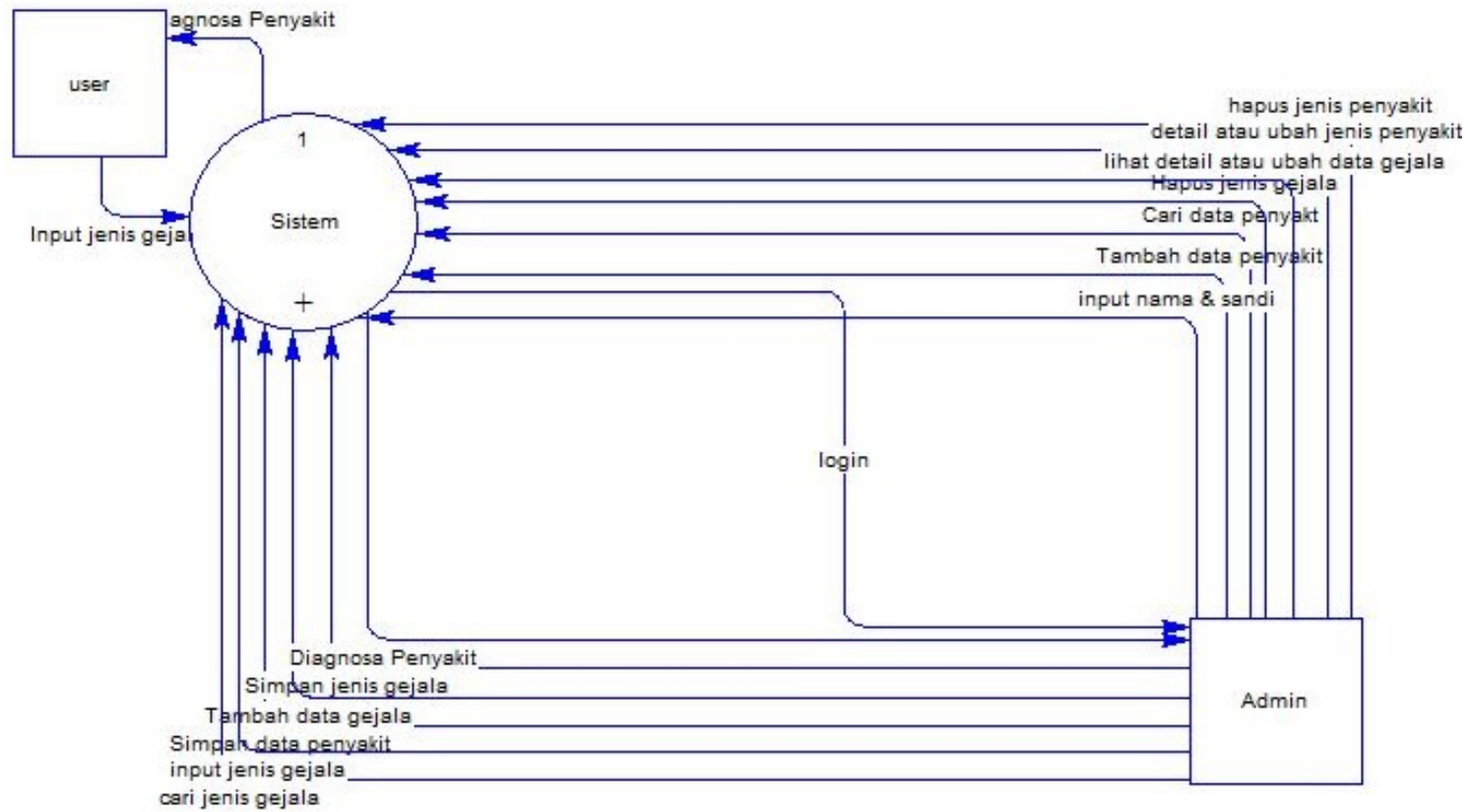

Gambar 2 Data Flow Diagram Level 0

\subsection{AlurSite Map}

Alur Site Mapdari sistem dipisah menjadi dua yaitu alur sebagai pengguna dan sebagai admin.Alur sebagai pengguna di mulai dengan mengakses Form Deteksi lalu muncul hasil deteksi yang dilakukan.Sedangkan pada alur sebagai admin dimulai dengan mengakses Form Login kemudian ada beberapa menu yang dapat diakses antara lain Pengaturan, Kunci Akun, Gejala, Penyakit, dan Deteksi.Menu Pengaturan digunakan untuk mengature data admin.Menu Kunci Akun digunakan untuk mengunci akun admin.Menu Gejala digunakan untuk menambahkan data gejala.Menu Penyakit digunakan untuk menambahkan data jenis penyakit.Menu Deteksi digunakan untuk melakukan deteksi penyakit kambing. Alur Site Map yang diajukan ditunjukkan pada Gambar 3.

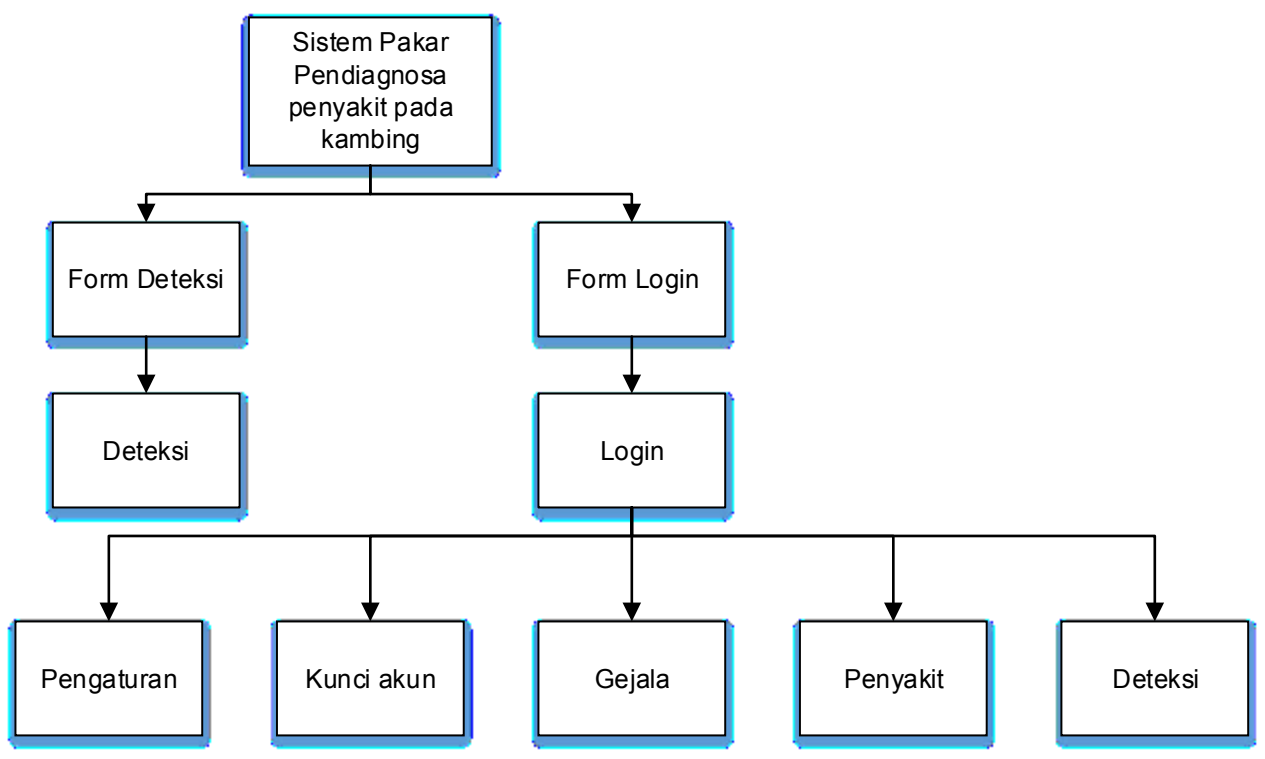

Gambar 3 Alur Site Map 


\section{HASIL PENGUJIAN METODE}

Pengujian metode forward chaining untuk mendeteksi penyakit pada kambing dilakukan pada 16 jenis penyakit seperti yang ditunjukkan pada Tabel 2.Pada pengujian ini, semua model pertanyaan akan diuji. Setiap model pertanyaan mewakili pengujian pada rule 1 sampai 16 . Setelah pengujian model pertanyaan dilakukan, akan dihitung prosentase keberhasilan dari metode forward chaining yang dimodelkan untuk mendeteksi penyakit pada kambing. Contoh model pertanyaan dan jawaban pada rule 1ditunjukkan pada Tabel 5. Pata pada Tabel 5 ditunjukkan hasil jawaban yang diajukan oleh user.Pertanyaan yang diajukan sesuai dengan daftar pertanyaan yang telah dibuat sebelumnya.Dari jawaban yang diperoleh, hanya jawaban "Ya" saja yang masuk kedalam rule, yaitu rule 1.Sehingga hasil diagnosa yang dihasilkan adalah penyakit "Diare".

Tabel 5 Pengujian pada Model Pertanyaan 1

\begin{tabular}{lll}
\hline \multicolumn{1}{c}{ Kode Gejala } & \multicolumn{1}{c}{ Gejala yang Masuk } & \multicolumn{1}{c}{ Jawaban User } \\
\hline G18 & Nafsu makan hilang & Tidak \\
G03 & Ya \\
G01 & Yuhu Tubuh meninggi & Ya \\
G02 & Kambing lesu & Ya \\
G04 & Kambing tidak menyusu & Ya \\
\hline \hline
\end{tabular}

Dari 16 model pertanyaan yang sudah diuji, didapatkan hasil pengujian yang ditunjukkan pada Tabel 6.Berdasarkan hasil dari model pertanyaan yang diuji, nilai akurasi dihitung dengan rumus yang ditunjukkan pada Persamaan 1(Orisa, Santoso, Setyawati, 2014).

Tabel 6 Hasil Pertanyaan yang Diuji

\begin{tabular}{llll}
\hline \hline $\begin{array}{c}\text { Model } \\
\text { Pertanyaan }\end{array}$ & \multicolumn{1}{c}{ Hasil Sistem } & \multicolumn{1}{c}{ Hasil Sebenarnya } & Hasil Prediksi \\
\hline 1 & Diare & Diare & \\
2 & Radang pusar & Radang pusar & Benar \\
3 & Cacar mulut & Cacar mulut & Benar \\
4 & Hipocalsemia & Hipocalsemia & Benar \\
5 & Radang Limpha & Radang Limpha & Benar \\
6 & PMK & PMK & Benar \\
7 & Septicaemia Epizootica & Septicaemia Epizootica & Benar \\
8 & Tympany & Tympany & Benar \\
9 & Parasit cacing hati & Parasit cacing hati & Benar \\
10 & Parasit cacing gelang & Parasit cacing gelang & Benar \\
11 & Parasit cacing lambung & Parasit cacing lambung & Benar \\
12 & Parasit cacing mata & Parasit cacing mata & Benar \\
13 & Scabies & Scabies & Benar \\
14 & Dermatitis & Dermatitis & Benar \\
15 & Pneumonia & Pneumonia & Benar \\
16 & Mastitis & Mastitis & Benar \\
\hline \hline
\end{tabular}

$$
\text { Akurasi }=\frac{\sum n}{\sum n t} x 100 \%
$$

Keterangan:

$\sum n=$ Total hasil benar

$\sum n t=$ Total seluruh data

$$
\begin{gathered}
\text { Akurasi }=\frac{16}{16} \times 100 \% \\
=1 \times 1100 \% \\
=100 \%
\end{gathered}
$$

Metode forward chaining merupakan metode yang melakukan penelusuran terhadap gejala-gejala atau penyebab-penyebab, maka apabila rule yang dibuat sudah sesuai dengan data dari pakar maka kemungkinan akurasi sempurna atau 100\% bisa didapatkan(Wati \& Mardiana, 2014). Begitu juga dengan yang terjadi pada 
penelitian ini. Pada Tabel 6 menunjukkan bahwa semua hasil prediksi yang dilakukan oleh sistem sama dengan hasil prediksi yang dilakukan oleh pakar, sehingga didapatkan akurasi sebesar $100 \%$.

\section{IMPLEMENTASI SISTEM}

Setelah dilakukan pengujian terhadap metode, langkah selanjutnya adalah melakukan implementasi antarmuka.Dalam implementasi antarmuka, yang dapat masuk ke Form Deteksi adalah semua pengguna peternak kambing dengan skala kecil ataupun besar.Sedangkan untuk Form Login hanya adalah Dokter Hewan.Implementasi antarmuka dari setiap menu ditunjukkan pada Gambar 4 - Gambar 7:
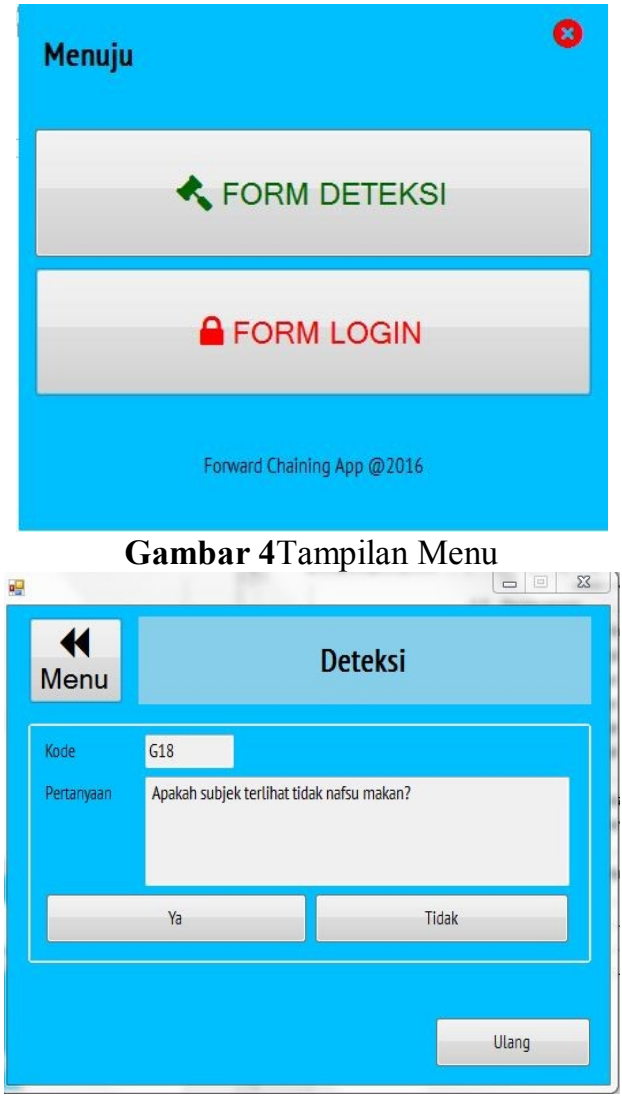

Gambar 5 Tampilan Form Deteksi

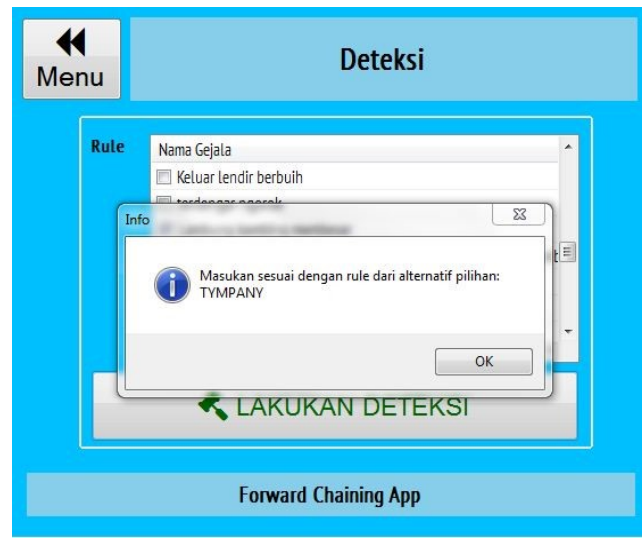

Gambar 6 Tampilan Hasil Deteksi

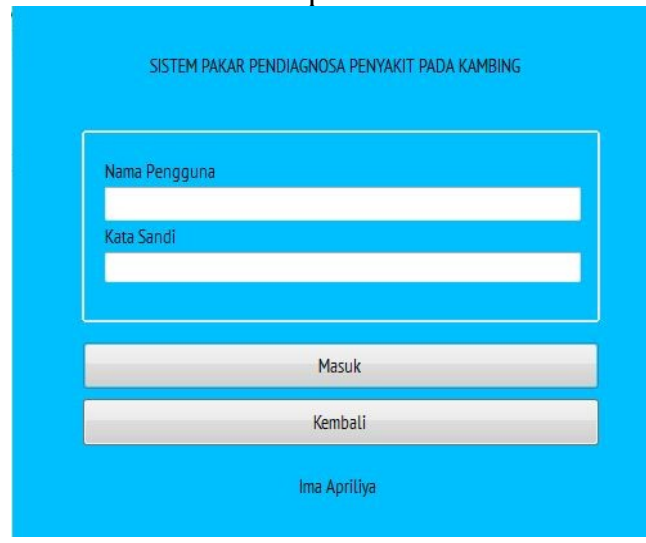

Gambar 7 Tampilan Form Login

\section{KESIMPULAN}

Sistem Diagnosis Penyakit pada Kambing dirancang dengan metode rule base dan inferensi forward chaining. Jumlah rule yang digunakan sebanyak 16 rule dengan 43 jenis pertanyaan sesuai dengan jumlah gejala.Pembuatan aplikasi sistem pakar untuk mendiagnosis penyakit kambing sudah berhasil mendeteksi ke16 jenis penyakit dengan akurasi mencapai $100 \%$. Pada penelitian selanjutnya model ini dapat digunakan pada data lain selain penyakit pada kambing. Selain itu, metode forward chaining bisa digabung dengan pembobotan certainty factor untuk menghasilkan keputusan yang lebih pasti(Wahyuni \& Kusumawati, 2017). Pembuatan rule pada metode forward chaining juga bisa dioptimasi menggunakan algoritma evolusi salah satunya adalah particle swarm optimization(Wahyuni, Auliya, Rahmi, \& Mahmudy, 2016).

\section{DAFTAR PUSTAKA}

Brady, M., \& Loonam, J. (2010). Exploring the use of entity-relationship diagramming as a technique to support grounded theory inquiry. Bradford: Emerald Group Publishing.

Diwyanto, K., Priyanti, A., \& Inounu, I. (2005). Prospek dan arah pengembangan komoditas peternakan: unggas, sapi dan kambing-domba. Wartazoa, 15(1), 11-25.

Djajanegara, A., \& Misniwaty, A. (2002). Pengembangan Usaha Kambing Dalam Konteks Sosial-Budaya 
Masyarakat. Lokakarya Nasional Kambing Potong, 121-126.

Kusumadewi, S. (2010). Logika Fuzzy. Jakarta: Pusaka Ilmu.

Nurdiansyah, R., Destiani, D., \& Retnadi, E. (2013). Perancangan Sistem Pakar Diagnosis Penyakit Domba. Jurnal SST-Garut, 10(1), 1-8.

Nurhakim, S. (2014). Mamalia, Lebih Dekat dengan Makhluk Menyusui. Jakarta: Bestari.

Orisa, M., Santoso, P. B., \& Setyawati, O. (2014). Sistem Pakar Diagnosis Penyakit Kambing Berbasis Web Menggunakan Metode Certainty Factor. Jurnal EECCIS, 8(2), 151-156.

Turban, E. (1995). Decision Support System and Expert System. New Jersey: Prentice Hall International.

Wahyuni, I., Auliya, Y. A., Rahmi, A., \& Mahmudy, W. F. (2016). Clustering Nasabah Bank Berdasarkan Tingkat Likuiditas Menggunakan Hybrid Particle Swarm Optimization dengan K-Means, 10(2), $24-33$.

Wahyuni, I., \& Kusumawati, C. (2017). Diagnosis Penyakit Infeksi Saluran Pernapasan pada Anak Menggunakan Forward Chaining dan Certainty Factor. Seminar Nasional Inovasi Teknologi UN PGRI Kediri, 1(2), 427-434.

Wati, E. W., \& Mardiana, T. (2014). Penerapan Sistem Pakar Untuk Mendeteksi Pendarahan Pada Masa Kehamilan. Jurnal Pilar Nusa Mandiri, X(1), 10-21. 